\title{
¿Artesonados mudéjares? \\ De algunas cuestiones terminológicas \\ e investigadoras en los estudios sobre \\ carpintería de armar española
}

\author{
Joaquín García NistaL \\ Universidad de León. Departamento de Patrimonio Artístico y Documental
}

\begin{abstract}
RESUMEN
La pregunta con la que se inicia el título de este artículo pretende cuestionar el correcto uso de algunos de los términos más empleados por la historiografía dedicada al estudio de la carpintería de armar española. La tradicional adscripción de estos trabajos de madera al estilo mudéjar también ha desembocado con frecuencia en una falta de precisión clasificatoria y en el ensombrecimiento de otras realidades culturales y arquitectónicas que los hicieron posibles.
\end{abstract}

Palabras clave: Artesonados; mudéjar; carpintería de armar.

\section{Mudejar coffered ceilings?. About some terminological and investigative questions in the spanish carpentry studies}

\begin{abstract}
The tittle`s question intends to argue the use of some of the most usual adjetives in the spanish carpentry studies. The qualifying mudejar used to this wooden works has caused, usually, a lack of precision in its classification and has became gloomy other cultural and architectural realities that made them possible.
\end{abstract}

Keywords: coffered ceiling; mudejar; carpentry.

No es infrecuente aún hoy encontrar expresiones como artesonados mudéjares para definir algunos ejemplares de la carpintería de armar española. Y no debe resultar extraño que se hayan acuñado tan desacertadas voces y que su uso haya sido prolongado e indiscriminado si atendemos al sólido sedimento que la historiografía dedicada a esta parcela de nuestro patrimonio ha dejado a lo largo del tiempo. No hay más que acercarse al hito fundacional de El estilo mudéjar en arquitectura, llevado a cabo en forma de discurso de ingreso a la Real Academia de Bellas Artes de San Fernando por José Amador de los Ríos en 1859, para entender el peso que han adquirido y la difícil tarea que supone la erradicación de algunos tópicos. 
En su exaltación del "maravilloso espectáculo... que ofrece... la civilización española" durante los tiempos en los que "estaba ya vencido para siempre el islamismo de Occidente" y se hizo posible la aparición de la "raza mudéjar", de los Ríos alaba el ejercicio de las artes de estos "vasallos", que incluso superó la venida de estilos como "el plateresco" con "maravillosos consorcios". Tanto fue así que el mudéjar se convertiría en "dueño... de la decoración de los artesonados, cualesquiera que fuese su traza, proseguía dotándolos de lazos, florones, estrellas, recuadros, tenas, arcos y bóvedas estalactíticas, mostrando en tal manera la indestructible fuerza de la tradición y consagrando el luminoso principio de crítica, por el cual reconocemos que jamás desaparece de las esferas de la civilización una idea, que haya tomado forma en artes o en letras, sin que legue al morir preciosas reliquias a la idea que viene a reemplazarla" 2 . Con estas afirmaciones, las armaduras de cubierta, agrupadas bajo el epígrafe artesonados, no solo pasarían desde entonces a estar indisolublemente asociadas al mudéjar "cualesquiera que fuese su traza", sino que además se proponía para este estilo un arco cronológico de influencia tan amplio que incluso "llega hasta nuestros días, tanto en las esferas arquitectónicas como en las industriales"3. Bajo esta perspectiva planteada por el baenense, casi resulta extraño que hubiera que esperar alrededor de noventa años para que un autor lo incluyera, ya puesta en duda su condición de estilo, dentro de unos Invariantes castizos de la arquitectura española ${ }^{4}$.

Lejos de que las imprecisiones de De los Ríos se corrigieran en lo sucesivo, hecho que hubiera sido más que plausible si se hubiera acometido un análisis riguroso del Breve compendio de la carpintería de lo blanco del alarife sevillano Diego López de Arenas - que ya era bien conocido entonces e incluso aparece mencionado en su discurso ${ }^{5}$-, éstas continuaron con posterioridad. Cuando "artesonado" no designaba

1 AMADOR DE LOS RÍOS, José, El estilo mudéjar en arquitectura. Discurso del Excmo. Sr. Don José Amador de los Ríos leído en la Junta Pública de 19 de junio de 1859..., Valencia, Librerías París-Valencia, 1996 (1872), pp. 11-12. Quisiera expresar aquí mi agradecimiento a Da Vanessa Jimeno Guerra (Universidad de León), por su constante ayuda y recomendaciones en lo académico y en lo personal.

2 Ibid., p. 36.

3 Ibid., p. 39.

4 Nos referimos a la monografía de CHUECA GOITIA, Fernando, Invariantes castizos de la arquitectura española, Madrid, Seminarios y Ediciones, 1971 (1947).

5 La primera edición impresa de este breve compendio fue realizada en Sevilla en 1633, en los talleres de Luís Estupiñán. LÓPEZ DE ARENAS, Diego, Breve compendio de la carpintería de lo blanco, y tratado de alarifes, con la conclusión de la regla de Nicolás Tartaglia, y otras cosas tocantes a la Geometría, y puntas del compás..., Sevilla, Luís Estupiñán, 1633. Sobre las diferentes ediciones del mismo, vid. el estudio introductorio de $\mathrm{M}^{\mathrm{a}}$ Ángeles Toajas Roger en Id., Breve compendio de la carpintería de lo Blanco y tratado de alarifes. Edición anotada y estudio preliminar de María Ángeles Toajas Roger, Madrid, Visor Libros, 1997, pp. 40-61; PACIOS LOZANO, Ana Reyes, Bibliografia de arquitectura y techumbres mudéjares, Teruel, Instituto de Estudios Turolenses, 1993, pp. 81-83 e Id., Bibliografía del arte mudéjar: Addenda (1992-2002), Teruel, Centro de Estudios Mudéjares, 2002, pp. 40-41. En cuanto a la mención relativa al texto de Arenas que lleva a cabo José Amador de los Ríos, éste cita: "Diego López de Arenas, constructor afortunado de crecido número de alfarjes,... recogía en su Arte de Carpintería de lo Blanco el fruto de su larga experiencia y los consejos de sus mayores", AMADOR DE LOS RÍOS, José (1996), op. cit., p. 37. 
la totalidad de estos trabajos lignarios, hacía referencia a la forma de artesa que presentaba el resultado formal de algunos de ellos ${ }^{6} ; \mathrm{y}$ ha sido esta última formulación la que ha alcanzado tal grado de fortuna que todavía puede rastrearse en la actualidad.

Felizmente, la especialización de las investigaciones, particularmente desde la década de los ochenta del pasado siglo, redujo la aplicación de este término casi exclusivamente a aquellas obras integradas por artesones 7 . Se renunciaba así a las valoraciones formalistas tan habituales entre los historiadores del arte precedentes, pero aún se continuaba presentando como un modelo autónomo dentro de las clasificaciones estructurales. Habría que esperar a la llegada de estudios recientes para que la voz artesonado pasara a designar únicamente un tipo de solución complementaria y, de este modo, desapareciera de las categorizaciones anteriores ${ }^{8}$.

\section{El "indisociable" calificativo mudéjar}

Más dificultades plantea erradicar la aplicación del adjetivo mudéjar a la práctica totalidad de estos trabajos, aun en casos absolutamente injustificables en los que parece haberse acuñado la máxima de Amador de los Ríos por la que "fuese cual fuese su traza" eran siervos de este estilo'. Aunque el debate sobre la paternidad de algunos tipos estructurales de la carpintería de armar peninsular no puede considerarse cerrado ${ }^{10}$, existe unanimidad, en cambio, sobre el importante papel que, en

6 En este sentido podemos destacar algunos ejemplos tempranos, como el capítulo dedicado al estilo mudéjar en LAMPÉREZ Y ROMEA, Vicente, Historia de la Arquitectura Cristiana Española en la Edad Media, t. II, Valladolid, Ámbito, 1999 (1906), pp. 531-615, en el que afirma: "Las armaduras mudéjares se llaman, en general, alfarjes,... la forma general es la de una A, de la cual interiormente no aparece más que los planos inclinados y horizontal, de cuya silueta les viene a estas armaduras el nombre de artesón”, Ibid., p. 563. Por su parte, Josep F. Ràfols, en la que puede considerarse como la primera monografía en plantear una clasificación sistemática para nuestra carpintería de armar, incluye los artesonados como una tipología estructural independiente, sobre los que determina que "si bien el nombre de artesonados se puede aplicar a todas las techumbres y considerarse las de pares y nudillo como si fueran constituidas por una gran artesa, más propio es dar este nombre a aquellas obras de carpintería que... están compuestas por maderos entrecortados que dejan entre sí hondos espacios regulares de los cuales penden florones u otros elementos de talla", RÀFOLS, Josep Francesc, Techumbres y artesonados españoles, Barcelona-Buenos Aires, Labor, 1926, p. 74.

7 Ejemplo de ello es la inclusión de artesonados, por parte de Enrique Nuere, dentro del capítulo de soluciones constructivas de los suelos o pisos, en la que constituye una de las contribuciones más valiosas al estudio de la carpintería de armar española. Para este autor, "entre los forjados de piso se encuentran los artesonados", que no son sino "los forjados resueltos con esta solución [la de emplear artesones entre los elementos integrantes de los mismos]”. NUERE MATAUCO, Enrique, La carpintería de armar española, Madrid, Instituto Español de Arquitectura, 2000 (1989), pp. 53 y 66. El encorchetado de la cita es nuestro.

8 Cabe destacar aquí las aportaciones de FERNÁNDEZ CABO, Miguel, Armaduras de cubierta, Valladolid, Ámbito, 1997, pp. 100-104. Establece una clasificación de las soluciones constructivas de los paños para definir cómo se resuelven las entrecalles, por lo que el calificativo artesonado debe entenderse, como las soluciones de cinta y saetino, ataujeradas, apeinazadas, etc., dentro de una clasificación complementaria a la estructural y formal, pero independiente de éstas y nunca suficiente sin las anteriores.

9 vid. nota 2 del presente estudio.

10 Para no realizar aquí una interminable relación de los estudios dedicados a este capítulo de nuestra carpintería de armar, indicamos la existencia de dos directrices perfectamente diferenciadas. Por una parte 
el desarrollo y transformación de los mismos, tuvo la incorporación de diferentes repertorios geométricos procedentes de al-Andalus a los elementos resistentes de las armaduras de cubierta y la adaptación de estos últimos a los anteriores.

Con independencia del origen étnico de sus ejecutores y obviando la problemática establecida en torno a cuál fue el ámbito peninsular en que se gestaron los primeros ejemplos de nuestra carpintería de 1 lazo $^{11}$, creemos acertado calificar algunos de ellos como mudéjares, entendidos en su amplio sentido de partícipes de la cultura mudéjar que se gesta en los territorios cristianos de la Hispania medieval. En este sentido, cabe destacar el nutrido número de investigaciones que ha señalado el notable cometido que el clientelismo monárquico y nobiliario del norte peninsular desempeñó a la hora configurar un particular escenario cultural durante la Baja Edad Media, gracias a la demanda, importación e imitación de las tradiciones culturales, constructivas y artísticas andalusíes ${ }^{12}$.

las investigaciones que tradicionalmente han otorgado unos patrones hispano-musulmanes para el origen y desarrollo de determinados modelos constructivos y decorativos, y, por otra, las que sitúan el germen de los mismos en los modelos de la carpintería europea o propiamente hispana. Dentro de las primeras el grupo es numeroso y principalmente han venido respaldándose en el hecho de que la más antigua de las armaduras de pares conservada se halle en la mezquita de la Kutubiyya en Marrakech. Vid. TORRES BALBÁS, Leopoldo, "Restos de una techumbre de carpintería musulmana en la iglesia de San Millán de Segovia", en Al-Andalus, no 3, 1935, pp. 429-430 y MARTÍNEZ CAVIRÓ, Balbina, "Hacia un corpus de la carpintería de lo blanco", en Actas del II Simposio Internacional de Mudejarismo (Teruel, 1981), Teruel, Instituto de Estudios Turolenses, 1982, pp. 125-132. Entre las segundas, se ha apuntado una numerosa relación de posibilidades que varían entre la paternidad de origen clásico, hispano-visigodo o centroeuropeo. Por citar algunos ejemplos destacamos: BYNE, Arthur y STAPLEY, Mildred, Decorated wooden cewilings in Spain: A collections of photographs and measured drawings with descriptive text, New York-London, G. P. Putnam`s Sons, 1920, pp. 23 y ss.; PRIETO Y VIVES, Antonio, "La carpintería hispanomusulmana", en Arquitectura, $\mathrm{n}^{\circ}$ 161-162, 1932, pp. 265-302; NUERE MATAUCO, Enrique, La carpintería de lo blanco. Lectura dibujada del primer manuscrito de Diego López de Arenas, Madrid, Ministerio de Cultura, 1985 e Id., "Los cartabones como instrumento exclusivo para el trazado de lacerías", en Madrider Mitteilungen, $\mathrm{n}^{\circ}$ 23, 1982, pp. 372-427.

11 Frente a la hipótesis más generalizada que sitúa los orígenes de la incorporación de trazados de lacería en la carpintería andalusí, Enrique Nuere abrió una nueva vertiente de opinión al proponer que debieron ser los carpinteros castellanos quienes contaron con las facilidades aportadas por sus estructuras reticulares y el sistema constructivo de cartabones, por lo que debe ser a estos últimos a quienes se debe tal logro. NUERE MATAUCO, Enrique (2000), op. cit., pp. 151 y 195.

12 Son abundantes las investigaciones sobre la apropiación de los espacios áulicos musulmanes por parte de los monarcas cristianos y la construcción de otros nuevos a imitación de los anteriores. Por citar algunas de ellas, destacamos ALMAGRO CORBEA, Antonio, "Los palacios de tradición andalusí en la Corona de Castilla: Las empresas de Pedro I”, en VALDÉS FERNÁNDEZ, Manuel (ed. y coord.), El legado de Al-Andalus. El arte andalusí en los reinos de León y Castilla durante la Edad Media (León, 2006), Valladolid, Fundación del Patrimonio Histórico de Castilla y León, 2007, pp. 245-281; PÉREZ HIGUERA, María Teresa, "El primer mudéjar castellano: casas y palacios", en NAVARRO PALAZÓN, Julio (ed.), Casas y Palacios en al-Ándalus (siglos XII y XIII), Barcelona, Lunwerg, 1995, pp. 303-314; PÉREZ HIGUERA, María Teresa, "El mudéjar, una opción artística en la Corte de Castilla y León”, en RIVERA BLANCO, José Javier (coord.), Historia del Arte de Castilla y León. Arte mudéjar, vol. IV, Valladolid, Ámbito, 1994, pp. 129-222; LAVADO PARADINAS, Pedro José, "El palacio mudéjar de Astudillo", en CALLEJA GONZÁLEZ, María Valentina (coord.), II Congreso de Historia de Palencia (Palencia, 1989), vol. I, Palencia, Diputación Provincial, 1990, pp. 579-599; CÓMEZ RAMOS, Rafael, El Alcázar del Rey don Pedro, Sevilla, Diputación Provincial de Sevilla, 2006 (1996); MORALES, Alfredo José, "El alcázar del rey don Pedro I y los palacios mudéjares sevillanos”, 
Varias son las razones se han expuesto para explicar esta singular modalidad de patrocinio regio ${ }^{13}$, especialmente para el enclave de la Corona de Castilla. A las relacionadas con los cambios de gusto de una monarquía que redescubría una nueva realidad artística al paso de la Reconquista, y con la búsqueda de emblemas victoriosos sobre el vencido que se esconde bajo las apropiaciones simbólicas y reales llevadas a cabo, debemos sumar otras más recientes que han visto en este hecho una estrategia para configurar una imagen característica y distintiva ${ }^{14}$. De este modo, sumergida en una profunda crisis, sometida a enfrentamientos con Aragón y en vías de una guerra civil, la Corona castellana encontró en el vasallo reino nazarí el modelo representativo que buscaba para el fortalecimiento del poder regio, especialmente durante los reinados de Pedro I (1350-†1369) y Enrique II (1369$\dagger 1379)^{15}$.

Al margen de los diferentes motivos que lo hicieron posible, los proyectos áulicos de estos y otros monarcas y las empresas privadas que la nobleza más afín realizaba a imitación de los anteriores harían posible el afianzamiento de la aculturación mudéjar de los reinos cristianos. Dentro de este escenario, y para el caso que nos ocupa, el empleo del término mudéjar como calificativo que sirva para determinar unos trabajos de carpintería asociados a este fenómeno puede considerarse adecuado $^{16}$. No en vano, las armaduras de cubierta vinculadas con estas empresas de promoción regia y nobiliaria de la Baja Edad Media constituyen una nómina tan extensa que en sí mismas son un verdadero compendio de la evolución estructural y ornamental que alcanzaron gracias a la incorporación de repertorios decorativos

en LACARRA DUCAY, María del Carmen (coord.), Arte mudéjar en Aragón, León, Castilla, Extremadura y Andalucía, Zaragoza, Institución "Fernando el Católico", 2006, pp. 233-260.

${ }^{13}$ La importancia que tuvo este particular clientelismo regio en la formación de una cultura mudéjar ha sido estudiada por el profesor Valdés Fernández, quien pone de relieve las adquisiciones de numerosos objetos hispanomusulmanes que rodearon a los monarcas en vida y muerte. Vid. VALDÉS FERNÁNDEZ, Manuel, "La arquitectura mudéjar y los sistemas constructivos en los reinos de León y Castilla en torno a 1200", en LACARRA DUCAY, María del Carmen (2006), op. cit., pp. 65-110 e Id., "Clientes y promotores en la asimilación de modelos andalusíes en la Edad Media", en VALDÉS FERNÁNDEZ, Manuel (2007), op. cit., pp. 19-42.

${ }^{14}$ Este argumento ha sido expuesto por RUIZ SOUZA, Juan Carlos, "Castilla y Al-Andalus. Arquitecturas aljamiadas y otros grados de asimilación", en Anuario del Dpto. de Historia y Teoría del Arte (UAM), $\mathrm{n}^{\circ} 16$, 2004, pp. 17-43 y RUIZ SOUZA, Juan Carlos, "Al-Andalus y cultura visual. Santa María la Real de las Huelgas de Burgos y Santa Clara de Tordesillas: dos hitos en la asimilación de Al-Andalus en la reinteriorización de la Corona de Castilla y León”, en VALDÉS FERNÁNDEZ, Manuel (ed. y coord.), El legado de Al-Andalus. El arte andalusí en los reinos de León y Castilla durante la Edad Media (León, 2006), Valladolid, Fundación del Patrimonio Histórico de Castilla y León, 2007, pp. 205-242.

15 Ibid.

${ }^{16}$ En los esfuerzos por recuperar una terminología histórica tomada de documentos contemporáneos, se ha comprobado que el mudéjar, aunque presentado bajo la voz "morisco" o incluso "castellano", tuvo una valoración estilística frente a otras tendencias como "moderno", "a la romana", etc. Vid. MARÍAS, Fernando, "Reflexiones sobre las catedrales de España y Nueva España" en Ars Longa, n 5, 1994, pp. 244-245 y LÓPEZ GUZMÁN, Rafael, Arquitectura mudéjar. Del sincretismo medieval a las alternativas hispanoamericanas, Madrid, Cátedra, 2000, p. 17. 
procedentes del sur hispano, aun cuando contaban con una consolidada tradición constructiva en el área cristiana peninsular ${ }^{17}$.

\section{Otras opciones estilísticas en la carpintería de armar española}

Pero ya adelantamos que el uso de esta expresión ha sido abusivo e indebido en muchos casos. El afán de considerar al mudéjar como un estilo prácticamente intemporal ha derivado en que se haya propuesto esta denominación para casi cualquier trabajo de carpintería, especialmente para aquellos que adoptan algún motivo decorativo geométrico, sin advertir la profunda brecha que en muchos casos los separa de aquella realidad a la que nos hemos referido anteriormente.

No es aceptable, por tanto, que empleemos esta voz para especificar un determinado escenario cultural y arquitectónico, y no lo hagamos con otras para otros casos. Es injustificable que los alfarjes de las galerías oeste y norte del claustro bajo del monasterio de Santo Domingo de Silos (ca. 1366), el del Paraninfo de la Universidad de Alcalá de Henares (ca. 1516-1520) (fig. 1), los forjados de la "sala Gran Daurada" (fig. 2), "sala Chica Daurada" (ca. 1519-1535) y de la "sala



Fig. 1. Andrés de Zamora, Bartolomé Aguilar, Pedro Izquierdo y Hernando de Sahagún, alfarje con tornapuntas del Paraninfo de la Universidad, Alcalá de Henares (Madrid), ca. 1516-1520.

17 Sobre algunas de estas cuestiones relacionadas con la carpintería bajomedieval en la Corona de Castilla, vid. GARCÍA NISTAL, Joaquín, "Las armaduras de cubierta en la consolidación de una imagen para la Corona de Castilla durante el tercer cuarto del siglo XIV", en Boletín del Seminario de Estudios de Arte y Arqueología, Arte, nº 76, 2010, pp. 9-24. 


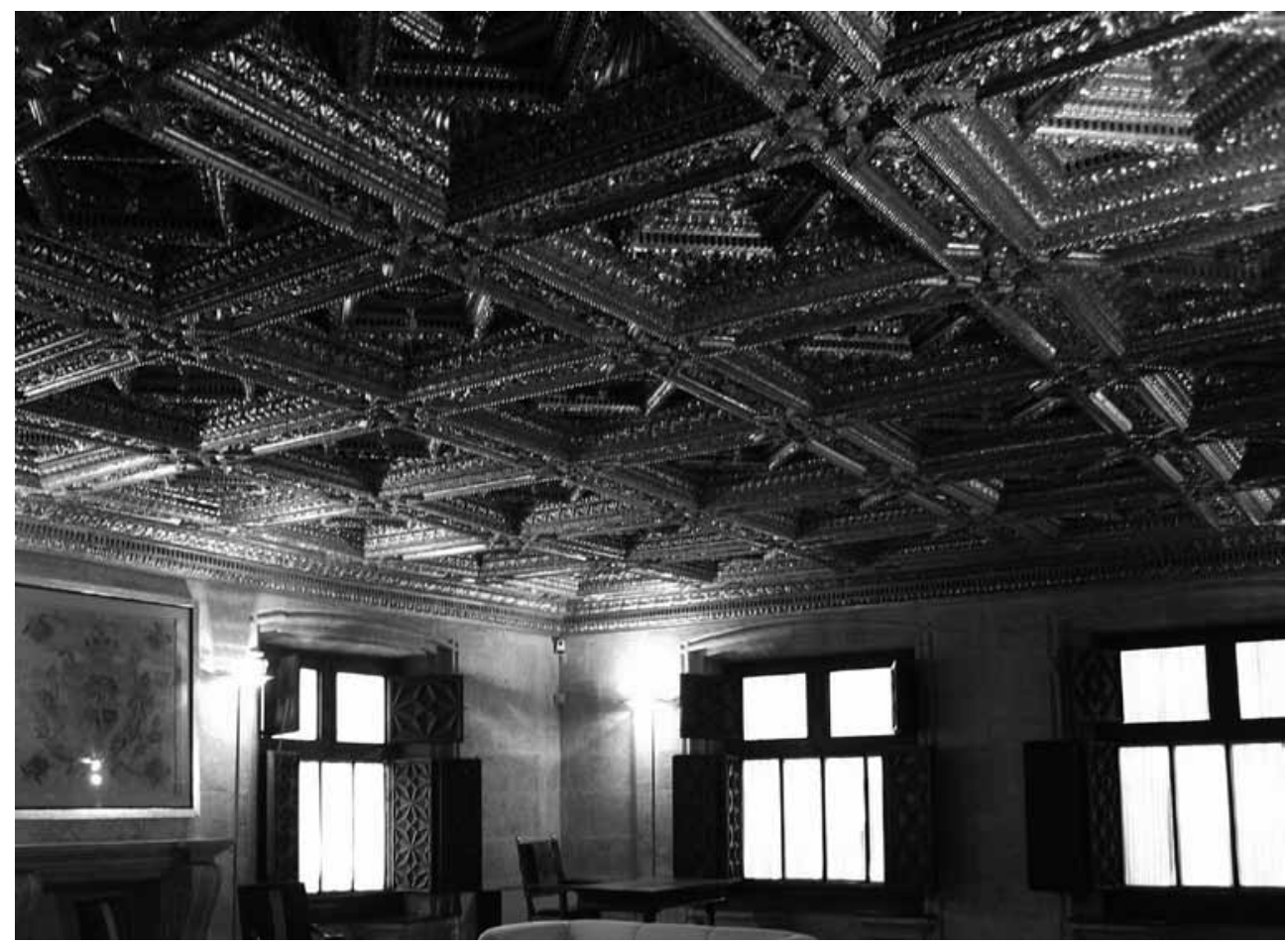

Fig. 2. Genís Linares, forjado de la Sala Gran Daurada del Torreón de la Generalitat, Valencia, ca. 1519-1534.

Nova" (ca. 1542-1566) del palacio de la Generalitat de Valencia, el de la sala capitular del antiguo convento de San Marcos de León (ca. 1542-1545) (fig. 3) o el del colegio de Fonseca en Santiago de Compostela (s. XVI), por citar algunos ejemplos bien conocidos, hayan sido adjetivados de mudéjares. La raíz de estas imprecisiones ha estado cimentada, principalmente, en el estudio superficial y exclusivamente formal de algunas investigaciones que han considerado suficiente el empleo de ornamentos de filiación hispanomusulmana como los mocárabes para adscribirlos a este estilo, cuando no ha sido únicamente el hecho de contener algún entramado geométrico, sean cuales sean sus características.

Lo cierto es que la realidad de la carpintería de armar española variaría desde el segundo cuarto del siglo XVI gracias a la incorporación de nuevos temas decorativos. Aunque probablemente éstos no provocaron un cambio tan significativo dentro de los tipos estructurales y morfológicos de la misma, sí promovieron una predilección por el uso de determinados modelos constructivos como los forjados ${ }^{18}, \mathrm{y}$, con

${ }_{18}$ El hecho de que numerosos de estos forjados del siglo XVI y XVII incorporen como refuerzo jabalcones o tornapuntas que trabajan a compresión axial ha provocado multitud de errores clasificatorios, ya que su resultado formal se asemeja al de algunas tipologías de armaduras de cubierta, especialmente de par y nudillo y de limabordón. 


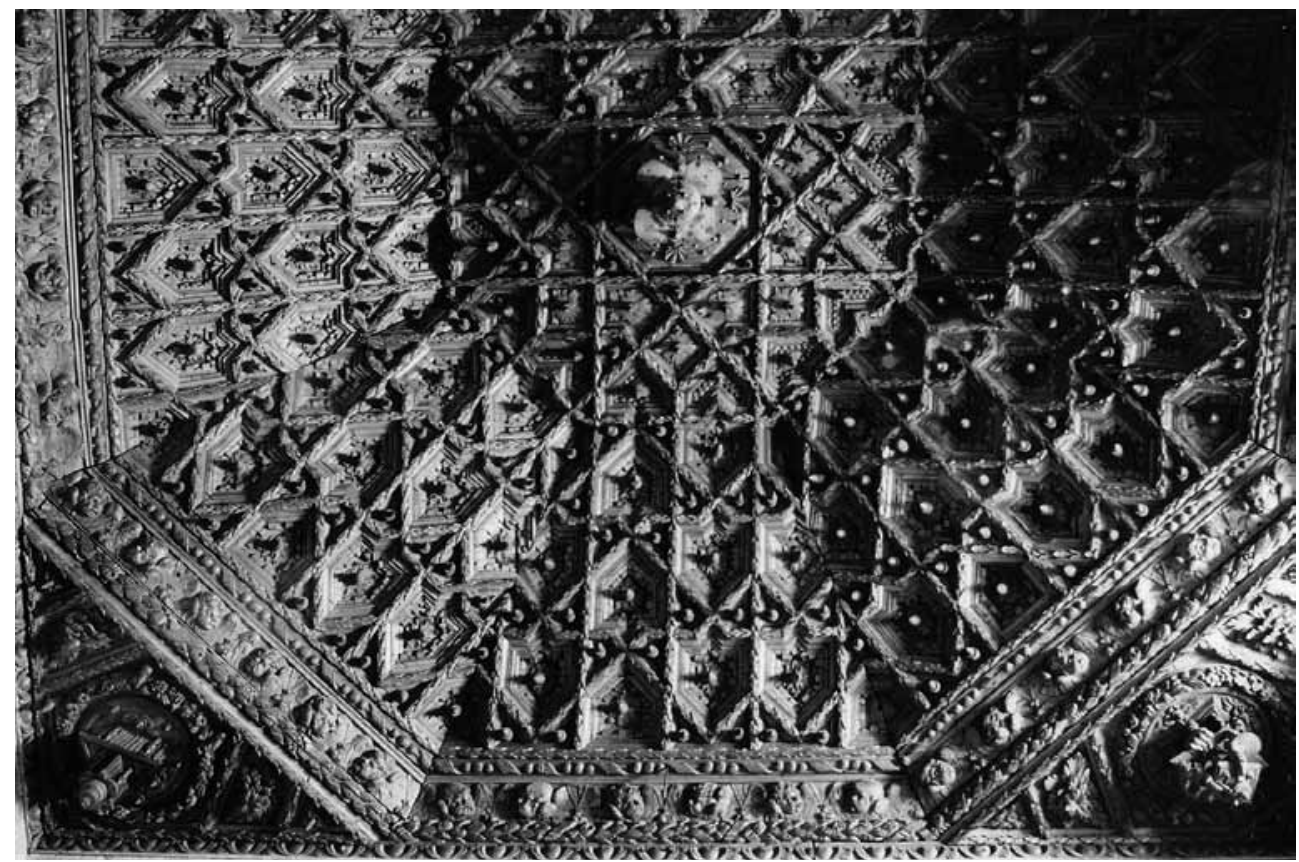

Fig. 3. Guillén Doncel, Pedro de la Tijera, Hernando de la Sota, Juan de Villaverde y Rodrigo de Villaverde, forjado con jabalcones de la sala capitular de San Marcos, León, ca. 1542-1545.

el empleo de artesones como solución para cuajar los espacios entre integrantes, permitieron establecer una mayor separación entre las vigas ${ }^{19}$, se potenciaron algunos resultados estéticos como los contrastes lumínicos y se evitó tanto el uso de grandes tablas como las problemáticas contracciones que ocasionaban. Cuando las nuevas tramas geométricas se integraron mediante la técnica ataujerada, los carpinteros tuvieron que enfrentarse a los mismos problemas que aquéllos que lo hicieron con las ruedas de lazo andalusíes, esto es, ajustar la traza a la inclinación de los paños y solventar los encuentros de la planimetría en las aristas y en los diferentes planos formados por los anteriores ${ }^{20}$.

Si indagar sobre los patrones ornamentales que los carpinteros medievales tuvieron como referencia para sus empresas se antoja como una ardua y poco fructífera tarea, ésta no resulta tan desoladora para los ejemplares del siglo

19 Esta mayor separación fue posible gracias a la homogeinización del comportamiento de los integrantes estructurales de los forjados, que generaban una retícula regular mediante en ensamblado perpendicular de peinazos. Sobre este aspecto remitimos a NUERE MATAUCO, Enrique (2000), op. cit., pp. 65-66.

20 Si bien es cierto que en muchas ocasiones, y con el fin de evitar riesgos de desajustes entre la traza geométrica y la estructura lignaria, se partía de la primera y, gracias al uso de la montea, se obtenían los cartabones necesarios para su ejecución y se definía la planimetría de los paños y el encuentro de los mismos con el almizate. Así se muestra en diferentes apartados de la obra de LÓPEZ DE ARENAS, Diego, Breve compendio de la carpintería de lo blanco y tratado de alarifes, Valencia, Albatros, 1982 (1633), ff. 24r.-33r. 
XVI. La edición de Medidas del romano de Diego de Sagredo en $1526^{21}$ o la del tratado de arquitectura de Sebastiano Serlio, especialmente en su traducción al castellano de los libros tercero y cuarto por Francisco Villalpando en $1552^{22}$, se convirtieron, entre otras, en una extraordinaria fuente de inspiración que puede rastrearse sin muchas dificultades por la totalidad de la geografía española.

Los repertorios de estas y otras publicaciones y los de las estampas, dibujos y grabados que sin duda circularon con asiduidad entre los maestros y oficiales de carpintería -muchos de ellos poseedores de bibliotecas donde constan algunas ediciones de los anteriores-, hicieron posible su reiteración. Cuando esta repetición se produce en un estrecho marco geográfico, inferimos generalmente que es producto de la actuación de algún taller, pero no debemos olvidar que en ocasiones aquélla es fruto de la copia directa, como se desprende de varios documentos en los que el comitente exige que la obra sea hecha "conforme a la de" una localidad cercana ${ }^{23}$. Sólo así se entiende la perdurabilidad en el tiempo de algunos entramados geométricos como el del forjado de la sala capitular de San Marcos de León. Su extensión por buena parte de la antigua Diócesis leonesa, tal como demuestran los ejemplares conservados en las parroquiales de Villamuñío, Mansilla Mayor, Valcabado del Páramo, Grijalba de Vidriales (Zamora), en la iglesia de San Esteban de Alija del Infantado o en la de Santa María de La Bañeza, desembocó en la inevitable atribución de todas estas obras a un importante taller itinerante. Pero la reciente concreción cronológica de las mismas, que abarca desde el modelo original capitalino ( $c a$.

${ }^{21}$ La primera edición fue impresa en Toledo. SAGREDO, Diego de, Medidas del Romano necesarias a los oficiales que quieren seguir..., Toledo, Ramón de Petras, 1526.

22 SERLIO, Sebastiano, Tercero y Quarto Libro de Architectura de Sebastian Serlio Boloñes... traduzido de Toscano en Romance Castellano por Francisco Villalpando Architecto, Toledo, Iván de Ayala,1552.

23 Utilizamos aquí una referencia inédita extraída de las condiciones de un contrato firmado en 1548 para realizar la armadura de cubierta de la iglesia parroquial de Bercianos del Real Camino (León). De manera continuada, y desde la primera de las condiciones de obra, se insiste en que se realice de igual forma en que está hecha la de la localidad de Pozuelos - que creemos hace referencia a Pozuelos del Rey (Palencia)-, tanto en dimensiones: "una capella con dos nabes, una al un costado e la otra a el otro. La capilla a de tener de bueco veynte y dos pies de la una parte y de la otra y a la lar[ga] del cuerpo veynte y ocho pies o veynte y siete de bueco conforme a la del de Pozuelos. Las nabes an de ser conformes a el labor de las de la dicha yglesia de pozuelos...", como en su decoración geométrica: "yten mas el casco de la capilla a de ser de lazo cuaxado conforme a la de Pozuelos". Archivo Histórico Diocesano de León (en adelante citado AHPL), Protocolos notariales de Andrés Pérez de Capillas, leg. 11 (1548-1549), s. f. Algo semejante se repite en la escritura de contrato de la armadura de la nave en la iglesia parroquial de San Pedro Castañero (León), en cuyas condiciones se indicaba que fuera realizada "conforme al maderamiento de la bera cruz de Villar de los Barrios de Salas... conforme a la labor e pintura de que está fecho el maderamiento de la dicha capilla de la veracruz...". También en la escritura del 27 de enero de 1590 para las obras de la capilla de la Vera Cruz, en Cacabelos (León), se exigía que "a de ser conforme a la Vera Cruz que está hecha en la entrada del lugar de Campo de Naraya...". AHPL, Protocolos notariales de Andrés Delgado, caja 1.481, leg. 19, ff. 104r.-107v. Documento transcrito en FERNÁNDEZ VÁZQUEZ, Vicente, Arquitectura religiosa en El Bierzo (s. XVI-XVIII), Ponferrada, I.V.E.-Fundación Ana Torres Villarino, 2001, pp. 689-691. 
1542-1545) hasta la armadura del presbiterio de Mansilla Mayor (1710) ${ }^{24}$, ha demostrado que la vía de la copia in situ debió de ser más habitual de lo que se había creído.

El alfarje de la sala capitular de San Marcos constituye, con todo, un excepcional testimonio de la novedosa situación por la que atraviesa la carpintería de armar desde el siglo XVI. Los repertorios ornamentales de raigambre clásica como las hojas de acanto, florones, guirnaldas o los frisos de ovas y dardo y de putti, se extienden por la totalidad de una superficie vertebrada por un lazo reticular de zafates harpados ${ }^{25}$. No obstante, con independencia de estas incorporaciones epidérmicas, este trabajo lignario debe valorarse, como lo hacíamos para el caso de los ejemplares mudéjares, en el contexto de su realidad cultural, que no es otro sino el que hizo posible la gestación de uno de los conjuntos monumentales pioneros en abrazar el lenguaje "del romano" en nuestro país ${ }^{26}$.

Las evidencias del nuevo panorama no solo son rastreables mediante los testimonios materiales conservados, sino también a través de los documentales. En los diferentes contratos de carpintería del Dieciséis se observa una creciente adopción de programas renacientes y el perfecto manejo de una nueva terminología. Las condiciones de obra exigían la realización de trabajos de carpintería en los que se incorporasen "moholdes de vytrones", "espejos redondos", "dentellones", "verdugos de romano" 27 , "verdugos entorexados", "molduras del romano", "florones", "filoteras", "pinjantes", "roleos" 28 , "artesones quajados de moldura relebada", "lenguas del romano" o "un quadrado en que bayan unos dentellones..." 29 . Además, viene a ser frecuente desde entonces que todo sea ejecutado "de maderamiento, y no de

24 Esta precisa datación la debemos a PACIOS LOZANO, Ana Reyes, Siete templos con armaduras mudéjares en la cuenca media del Esla, León, Diputación Provincial, 1990, pp. 24-109. Aunque se ha puesto en duda que el dato extraído de los libros de fábrica pueda hacer referencia a la construcción de la armadura, barajándose otras probabilidades como que se corresponda con una labor de reparación, los 960 reales que reciben los maestros de carpintería Francisco Sánchez y Valentín Díaz de la Portilla se ajusta al promedio de pago efectuado por techumbre para capilla mayor, tal y como hemos podido inferir del estudio de otras cartas de contrato del siglo XVIII.

25 Para un acercamiento en profundidad, vid. GARCÍA NISTAL, Joaquín, "El lazo reticular. Una solución constructivo-decorativa de la carpintería de lo blanco de la provincia de León", en Boletín Museo e Instituto “Camón Aznar" de Ibercaja, n 90, 2003, pp. 55-75.

${ }_{26}$ Sobre los aspectos artísticos y arquitectónicos del antiguo convento de San Marcos de León, vid. CAMPOS SÁNCHEZ-BORDONA, María Dolores, La arquitectura del renacimiento en la primera mitad del siglo XVI en la diócesis de León, León, Universidad de León, 1991 e Id., Juan de Badajoz y la arquitectura del Renacimiento en León, León, Universidad de León, 1993.

27 Términos extraídos del contrato de la armadura de cubierta de la iglesia de Villamizar (León) de 1549. AHDL., Protocolos notariales de Andrés Pérez de Capillas, leg. 11 (1548-1549), s. f.

28 Extraído del contrato de la techumbre para la iglesia de Bercianos del Real Camino (León) de 1548. Ibid., s. f.

29 Extraído de las condiciones de obra redactadas en 1554 para la elaboración de la armadura de la capilla de la Visitación en Salas de los Barrios (León). AHPL., Protocolos notariales. Sección Ponferrada, caja 1.501, leg. 42, ff. 160r.-163v. Documento transcrito en VOCES JOLÍAS, José María, Arte religioso de El Bierzo en el siglo XVI, Ponferrada, J. M. Voces, 1987 (1980), pp. 453-455. 
ninguna pyntura" ${ }^{30}$, otorgando así a sus obras un resultado más acorde con la búsqueda de la serenidad renacentista y su idea apolícroma de lo clásico.

La acogida de estos temas decorativos también suscitó algunos cambios desde el punto de vista constructivo, si bien no definieron nuevas variantes tipológicas dentro de la carpintería de armar. Aún cuando se continuó empleando la técnica ataujerada para ejecutar los entramados geométricos "del romano", en ocasiones, y debido a sus peculiaridades distributivas, éstos condicionaron el desarrollo estructural y morfológico de las techumbres, especialmente en el almizate y algunos faldones. Este es el caso de la armadura situada en la capilla mayor de la iglesia de San Clemente de Escobar de Campos (León) (fig. 4) y de la desaparecida de Lagunilla de la Vega (Palencia), para cuyos paños se eligió un lazo de retículo de composición continua, armónica y de gusto clásico, formado por estrellas de seis puntas que comparten algunos temas geométricos para su formación y generan hexágonos residuales ${ }^{31}$.

El modo de resolver ambos conjuntos de sección ochava ejemplifica el hacer de los carpinteros del siglo XVI. Frente al habitual uso de limas moamares, se optaba ahora por el desdoblamiento de una lima única, hecho que no devino en una transformación constructiva importante, pero sí desembocó en la paulatina desaparición de la lima doble o, al menos, en una notable reducción de su empleo. Asimismo, las

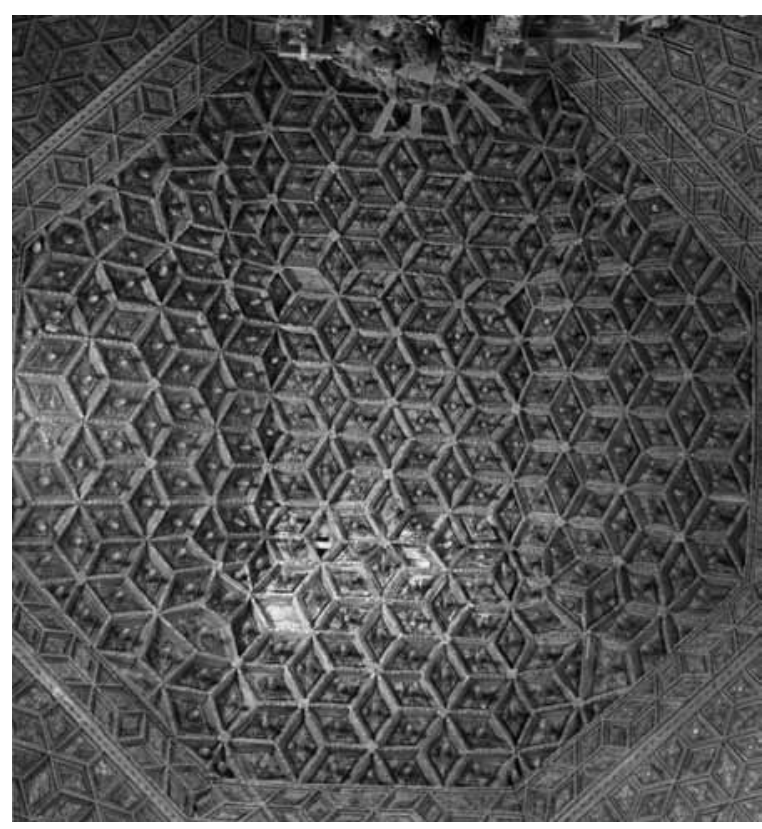

Fig. 4. Armadura de limas ochava con decoración ataujerada, Escobar de Campos (León), último tercio del siglo XVI.

30 Extraído de las condiciones de la armadura de cubierta para la iglesia de Trobajo del Camino (León). AHDL., Protocolos notariales de Juan de Pedrosa, leg. 6 (1522), s.f. Esta misma disposición aparece reflejada en el contrato para la realización de la techumbre de Columbrianos (León) de 1574: “...la guarniçión a de ser conforme a la capilla de San Sebastián, sin pintura”. AHPL., Protocolos notariales de Andrés Delgado. Sección Ponferrada, caja 1.481, leg. 19, ff. 104r.-107v. Documento trascrito en FERNÁNDEZ VÁZQUEZ, Vicente (2001), op. cit., pp. 689-691.

31 El tipo de lazo empleado es otra muestra más de la ordenación compositiva equilibrada que se encuentra presente, aunque con variantes, en otras carpinterías peninsulares como la ya mencionada del Paraninfo de la Universidad de Alcalá de Henares, en las armaduras de la iglesia de San Facundo y San Primitivo de la localidad de Cisneros (Palencia) y de la iglesia de Santa María en Castroverde de Campos (Zamora) o en repertorios de dibujos como los contenidos en el Libro Cuarto de Sebastiano Serlio. 
cualidades compositivas de este lazo, cuya regularidad sólo viene garantizada si se distribuye sobre un plano cuadrangular, condujo a sus autores a manejar un recurso nada frecuente en la carpintería de armar anterior: concebir harneruelos cuadrados que determinaron un diseño triangular para los cuatro faldones situados en los ángulos y otro cuadrangular para los cuatro restantes, sustituyendo así la tradicional opción de ocho gualderas trapezoidales y almizate octogonal.

Tampoco el secular anonimato de nuestra carpintería ha fomentado su pormenorizado conocimiento. El seguimiento de los maestros y oficiales de este oficio permite acercarnos con mayor certeza a las realidades arquitectónicas de diferentes períodos. Así ocurre con artífices como Hernando de la Sota, uno de los más activos maestros del ámbito leonés durante la primera mitad del siglo XVI, y quien ejemplifica a la perfección la cohabitación estilística que se produjo en este contexto.

Entre 1531 y 1532 planteaba para la armadura del presbiterio de la parroquial de Valdesaz de los Oteros (León) (fig. 5) una solución ornamental basada en la aplicación de ruedas de lazo de diez puntas $^{32}$, habitual en la carpintería mudéjar y andalusí. Una década después aparece mencionado junto con Pedro de la Tijera, Juan de Villaverde, Rodrigo de Villaverde y Guillén Doncel en la relación de trabajos llevados a cabo para el piso superior del claustro del convento de San Marcos de León ${ }^{33}$, en las que consta la realización de unos florones, botones y putti clásicos que también repetirían en el forjado de la sala capitular ${ }^{34}$. Pero este acercamiento al núcleo más destacado del Renacimiento leonés no supuso un abandono de los repertorios anteriores, pues en 1548 trazaba una "capilla ochavada de lazo cuaxada...

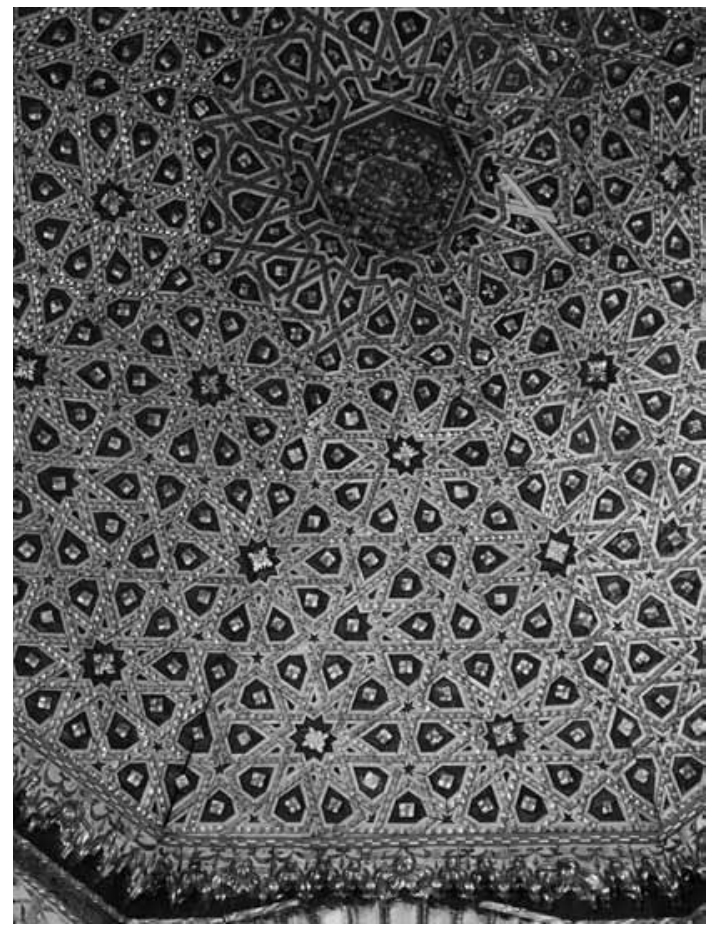

Fig. 5. Hernando de la Sota, armadura de limas ochava con lazo ataujerado, Valdesaz de los Oteros (León), 15311532.

32 Archivo Parroquial de Valdesaz de los Oteros (A.P.V.O.), Libro de fábrica, sf.

${ }^{33}$ CAMPOS SÁNCHEZ-BORDONA, María Dolores y ORICHETA GARCÍA, Arantzazu, "El convento de San Marcos de León. Nuevos datos documentales sobre el proceso constructivo en el siglo XVI", en Academia: Boletín de la Real Academia de las Bellas Artes de San Fernando, nº 86, 1998, pp. 258.

34 Vid. GARCÍA NISTAL, Joaquín (2003), op. cit., pp. 55-75. 
metida de su pintura y sus colores" y con florones "en los campos de las azafates" para la iglesia de San Pedro de El Burgo Ranero (León) ${ }^{35}$ y, un año más tarde, ejecutaba otra "de lazo cuaxado... de diez de almoyager" con "zafates... y sinos" ${ }^{36}$ para la de San Salvador de Bercianos del Real Camino (León). Si en estas armaduras Hernando de la Sota empleaba entramados decorativos que habitualmente se han asociado a las prácticas mudéjares, en este mismo año de 1549 proyectaba otra para la iglesia parroquial de Villamizar en la que se establece que la "guarnición a de ser de unos espejos redondos y en cada uno su moldura... con dentellón y atado de un verdugo de romano"37.

Esta breve relación es, a nuestro juicio, significativa de la variabilidad de opciones estilísticas que tienen lugar en este marco temporal, y de su coexistencia. Hecho que puede extrapolarse a otros ámbitos territoriales y cronológicos, puesto que los trabajos "a lo morisco", "a lo moderno" o "a lo romano" constituían alternativas que los profesionales de la carpintería de armar, gracias a su pericia técnica y al carácter eminentemente práctico de su oficio, barajaban con normalidad en función de diferentes variables como las necesidades de los espacios, la libertad de actuación, las pautas establecidas en las cartas de obligación y contrato, o la demanda, exigencia y gusto de sus promotores.

\footnotetext{
35 AHDL., Protocolos notariales de Andrés Pérez de Capillas, leg. 11 (1548-1549), s. f.

36 Ibid.

37 Ibid.
} 